S1

\title{
A Kinetic Monte Carlo Approach to Study Carbonate Dissolution
}

Supplementary (Supporting) Information

$$
\text { Inna Kurganskaya }{ }^{1, *} \text { and Andreas Luttge } e^{2,3}
$$

${ }^{1}$ Institue for Geological Sciences, University of Bern, Baltzerstrasse 3, 3012 Bern, Switzerland

\author{
${ }^{2}$ University of Bremen, MARUM and FB5, PO Box 330 440, 28334 Bremen, Germany \\ ${ }^{3}$ Rice University, Houston, TX 77005, USA
}

\section{Corresponding Author}

*Inna Kurganskaya, e-mail: inna.kurganskaya@geo.unibe.ch, Tel. +41 (0)31 6318787 
Calcite morphological unit cell. Input file data for XtalDraw program (the program is free of charge and can be found on http://www.geo.arizona.edu/xtal/group/software.htm). The input file is organized as follows:

Line 1: header and supporting information

Line 2: unit cell parameters, axis length in $\AA$, angles in ${ }^{\circ}$ : a b c $\alpha \beta \gamma$ space group Line 3: atom name

Line 4: coordinates in internal basis

...And so on.

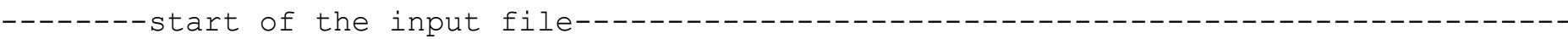

Author: Matthias Wagner. Calcite: Cleavage rhombohedral morphological cell for XtalDraw program - http://www.geo.arizona.edu/xtal/group/software.htm; cell parameters by Chang, Howie and Zussman in "Rock-Forming Minerals", 2nd ed., 1998, The Geological Society, Bath UK. $12.8512 .8512 .85101 .92101 .92101 .92 \mathrm{R}-3 \mathrm{C}$

$\mathrm{Ca}$

$\begin{array}{lll}0 & 0 & 0\end{array}$

$\mathrm{Ca}$

0.500

$\mathrm{Ca}$

0.250 .250

$\mathrm{Ca}$

0.750 .250

C

0.2500

C

0.250 .50

C

0.50 .250

$\mathrm{C}$

$\begin{array}{lll}0.25 & 0.25 & 0.25\end{array}$

C

$\begin{array}{llll}0.75 & 0.25 & 0.25\end{array}$

Anions

O

$\begin{array}{llll}0.32 & 0.18 & 0.25\end{array}$

0

$\begin{array}{lll}0 & 0.32 & 0.43\end{array}$

0

$\begin{array}{llll}0.25 & 0.07 & 0.43\end{array}$

0

$0.07 \quad 0.68 \quad 0$

0

$\begin{array}{lll}0 & 0.18 & 0.07\end{array}$

0

$\begin{array}{lll}0.25 & 0.43 & 0.57\end{array}$

0

$\begin{array}{llll}0.25 & 0.68 & 0.32\end{array}$

0

$\begin{array}{llll}0.75 & 0.18 & 0.32\end{array}$

0

$\begin{array}{llll}0.75 & 0.43 & 0.07\end{array}$

0

$\begin{array}{llll}0.5 & 0.68 & 0.07\end{array}$

End 